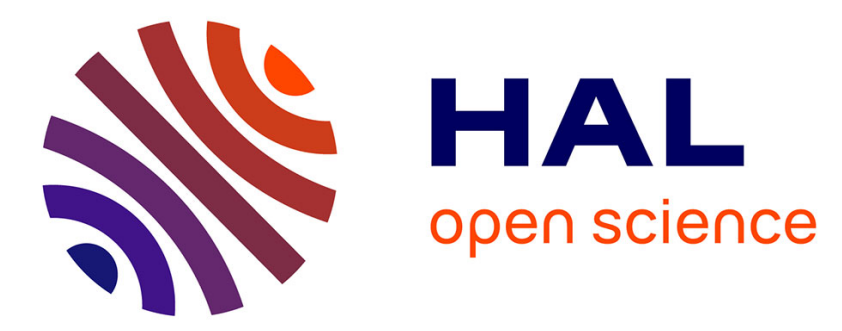

\title{
IMACLIM-R: a modelling framework to simulate sustainable development pathways
}

Jean Charles Hourcade, Olivier Sassi, Renaud Crassous, Vincent Gitz, Henri

Waisman, Céline Guivarch

\section{- To cite this version:}

Jean Charles Hourcade, Olivier Sassi, Renaud Crassous, Vincent Gitz, Henri Waisman, et al.. IMACLIM-R: a modelling framework to simulate sustainable development pathways. International Journal of Global Environmental Issues, 2010, 10 (1/2), pp.5-24. 10.1504/IJGENVI.2010.030566 . hal-00566290

\section{HAL Id: hal-00566290 \\ https://hal.science/hal-00566290}

Submitted on 15 Feb 2011

HAL is a multi-disciplinary open access archive for the deposit and dissemination of scientific research documents, whether they are published or not. The documents may come from teaching and research institutions in France or abroad, or from public or private research centers.
L'archive ouverte pluridisciplinaire HAL, est destinée au dépôt et à la diffusion de documents scientifiques de niveau recherche, publiés ou non, émanant des établissements d'enseignement et de recherche français ou étrangers, des laboratoires publics ou privés. 


\title{
IMACLIM-R: a modelling framework to simulate sustainable development pathways
}

\author{
Olivier Sassi*, Renaud Crassous, Jean-Charles Hourcade, Vincent Gitz, \\ Henri Waisman and Céline Guivarch \\ CIRED - Centre International de Recherche \\ sur l'Environnement et le Développement, \\ 45 bis avenue de la Belle Gabrielle, \\ 94736 Nogent sur Marne Cedex, France \\ E-mail: $\underline{\text { sassi@ } @ \text { centre-cired.fr }}$ \\ E-mail: crassous@ @entre-cired.fr \\ E-mail: hourcade@ centre-cired.fr \\ E-mail: gitz@centre-cired.fr \\ E-mail: waisman@centre-cired.fr \\ E-mail: guivarch@centre-cired.fr
}

${ }^{\star}$ Corresponding author

Reference to this paper should be made as follows: Sassi, O., Crassous, R., Hourcade, J-C., Gitz, V., Waisman, H. and Guivarch, C. (2010) 'TMACLIM-R: a modelling framework to simulate sustainable development pathways', Int. J. Global Environmental Issues, Vol. 10, Nos. 1/2, pp.5-24.

\section{Abstract :}

To assess the sustainability of future development pathways requires models to compute long-run Economy-Energy-Environment scenarios. This paper presents the IMACLIM-R framework, aimed at investigating climate, energy and development inter-related issues. The model was built in an attempt to address three methodological challenges: to incoporate knowledge from economics and engineering sciences, to support the dialogue with and between stakeholders, to produce scenarios with a strong consistency, concerning especially the interplay between development patterns, technology and growth. These goals led to the development of a recursive structure articulating a static general equilibrium framework including innovative features and sectorspecific dynamic modules now concerning energy, transportation and industry. This paper provides the general rationale of the model and the description of all its components.

\section{Keywords :}


Hybrid modelling, long-run, scenario, energy, climate, sustainability 
For economic modellers, the feverishness in the demands for studying sustainability issues represents an exciting challenge: to put some rationale in public debates about whether, when and why certain development pathways may be proven unsustainable, in spite of the uncertainty surrounding the unprecedented time horizons considered.

The risk of non sustainable development stems ultimately from the joint effect of issues as diverse as climate change, energy and food security, land cover changes or social dualism in urban and rural areas. These issues in turn depend on the dynamics of consumption and technologies in sectors such as energy, transportation, construction or food production and on the hazards caused by shortages of primary resources or by the transformation of our global environment. The challenge is thus to integrate sector-based analysis in a common economic framework capturing their interplay in a world experiencing very rapid demographic and economic transitions.

The IMACLIM-R structure presented in this paper meets this challenge through an integrated modelling approach (Weyant et al., 1996). Its primary aim is to provide an innovative framework that could organize better the dialogue between economics (to capture the general interdependences between sectors, issues and policy decisions), demography (to represent a major driver of the world economic trends), natural sciences (to capture the feedbacks of the alteration of the ecosystems) and engineering sciences (to capture the technical constraints and margins of freedom).

We first present the rationale of the IMACLIM-R structure. The second and third sections describe its static and dynamic components.

\section{Rationale and methodological choices behind the IMACLM-R architecture}

The overall rationale of IMACLIM-R stems from the necessity to understand better, amongst the drivers of baseline and policy scenarios, the relative role of (i) technical parameters in the supply 
side and in end-use equipments, (ii) structural changes in the final demand for goods and services (dematerialisation of growth patterns), (iii) micro and macroeconomic behavioural parameters in open economies. This is indeed critical to capture the mechanisms at play in the transformation of a given environmental alteration into an economic cost and in the widening or narrowing margins of freedom for mitigation or adaptation.

The specific way through which IMACLIM-R tries to reach this objective derives from a twofold diagnosis about the advances to make in designing baseline scenarios.

- The increasing recognition that endogenizing technical change to capture policy induced transformation of the set of available techniques should be broadened to the endogenization of structural change. As noted by Solow (1990) indeed, the rate and direction of technical progress depend not only on the efficiency of physical capital on the supply side but also on the structure of the final households' demand. Ultimately they depend upon the interplay between consumption styles, technologies and localization patterns. The point is that drastic departures from current trends possibly required by sustainability targets cannot but alter the very functioning of the macroeconomic growth engine.

- Although computable general equilibrium models represented great progress in understanding economic interdependences that are critical for the environment-economy interface, their limit is to study equilibrated growth pathways, often under perfect foresight assumptions. Nevertheless sustainability challenges come primarily from controversies about long term risks which can inhibit their internalization in due time and from the transition costs to adapt to unexpected hazards. This makes it necessary to describe an economy with disequilibrium mechanisms triggered by the interplay between inertia, imperfect foresight and 'routine' behaviours. For instance, an economy with structural debt or unemployment and submitted to volatile energy prices will not react in the same way to environmental shocks or policy intervention as an economy situated on a steady state growth pathway. 


\subsection{A Dual Vision of the Economy: an easier dialogue between engineers and economists}

IMACLIM-R is based on an explicit description of the economy both in money metric values and in physical quantities linked by a price vector ${ }^{1}$. This dual vision of the economy, which comes back to the Arrow-Debreu theoretical framework, is a precondition to guarantee that the projected economy is supported by a realistic technical background and, conversely, that any projected technical system corresponds to realistic economic flows and consistent sets of relative prices. The existence of explicit physical variables allows indeed a rigorous incorporation of sector based information about how final demand and technical systems are transformed by economic incentives, especially for very large departures from the reference scenario. This information encompasses (i) engineering based analysis about economies of scale, learning by doing mechanisms and saturation in efficiency progress (ii) expert views about the impact of incentive systems, market or institutional imperfections and the bounded rationality of economic behaviours.

But the full potential of this dual description could not be exploited without abandoning the conventional KLE or KLEM production functions which, after Berndt and Wood (1975) and Jorgenson (1981), were assumed to mimic the set of available techniques and the technical constraints impinging on an economy. Regardless of questions about their empirical robustness ${ }^{2}$, it remains that, whatever their mathematical form, they are calibrated on cost-shares data through Shepard's lemma. The domain within which this systematic use of the envelope theorem provides a robust approximation of real technical sets is limited by (i) the assumption that economic data,

\footnotetext{
${ }^{1}$ For the very subject of climate change mitigation, which implies the necessity to account for physical energy flows, modellers use so-called 'hybrid matrices' including consistent economic input-output tables and physical energy balances (see Sands et al., 2005). In Imaclim-R we aim at extending physical accounting to other non-energy relevant sectors such as transportation (passenger-kilometres, ton-kilometres) or industry (tons of steel, aluminium, cement).

${ }^{2}$ Having assessed one thousand econometric works on the capital-energy substitution, Frondel and Schmidt conclude that "inferences obtained from previous empirical analyses appear to be largely an artefact of cost shares and have little to do with statistical inference about technology relationship" (Frondel and Schmidt, 2002, p.72). This comes back to the Solow's warning that this 'wrinkle' is acceptable only at an aggregate level (for specific purposes) and implies to be cautious about the interpretation of the macroeconomic productions functions as referring to a specific technical content' (Solow, 1988, p. 313).
} 
at each point of time, result from an optimal response to the current price vector ${ }^{3}$ and (ii) the lack of technical realism of constant elasticities over the entire space of relative prices, production levels and time horizons under examination in sustainability issues. Even more important, the use of such production functions prevents models from addressing the path-dependency of technical change.

IMACLIM- $\mathrm{R}$ is thus based on the recognition that it is almost impossible to find functions with mathematical properties suited to cover large departures from a reference equilibrium over one century and flexible enough to encompass different scenarios of structural change resulting from the interplay between consumption styles, technologies and localization patterns (Hourcade, 1993). The absence of a formal production function is compensated for by a recursive structure that allows a systematic exchange of information between:

- An annual static equilibrium module, in which the production function mimics the Leontief specification, with fixed equipment stocks and fixed intensity of labour, energy and other intermediary inputs, but with a flexible utilization rate. Solving this equilibrium at $t$ provides a snapshot of the economy at this date, a set of information about relative prices, levels of output, physical flows and profitability rates for each sector and allocation of investments among sectors; - Dynamic modules, including demography, capital dynamics and sector-specific reduced forms of technology-rich models which take into account the economic values of the previous static equilibria, assess the reaction of technical systems and send back this information to the static module in the form of new input-output coefficients for calculating the equilibrium at $t+1$.

Each year, technical choices are flexible but they modify only at the margin the inputoutput coefficients and labour productivity embodied in the existing equipments that result from

3 "Total-factor-productivity calculations require not only that market prices can serve as a rough-and-ready approximation of marginal products, but that aggregation does not hopelessly distort these relationships." (Solow, 1988, p. 314) 
past technical choices. This general putty-clay ${ }^{4}$ assumption is critical to represent the inertia in technical systems and the role of volatility in economic signals.

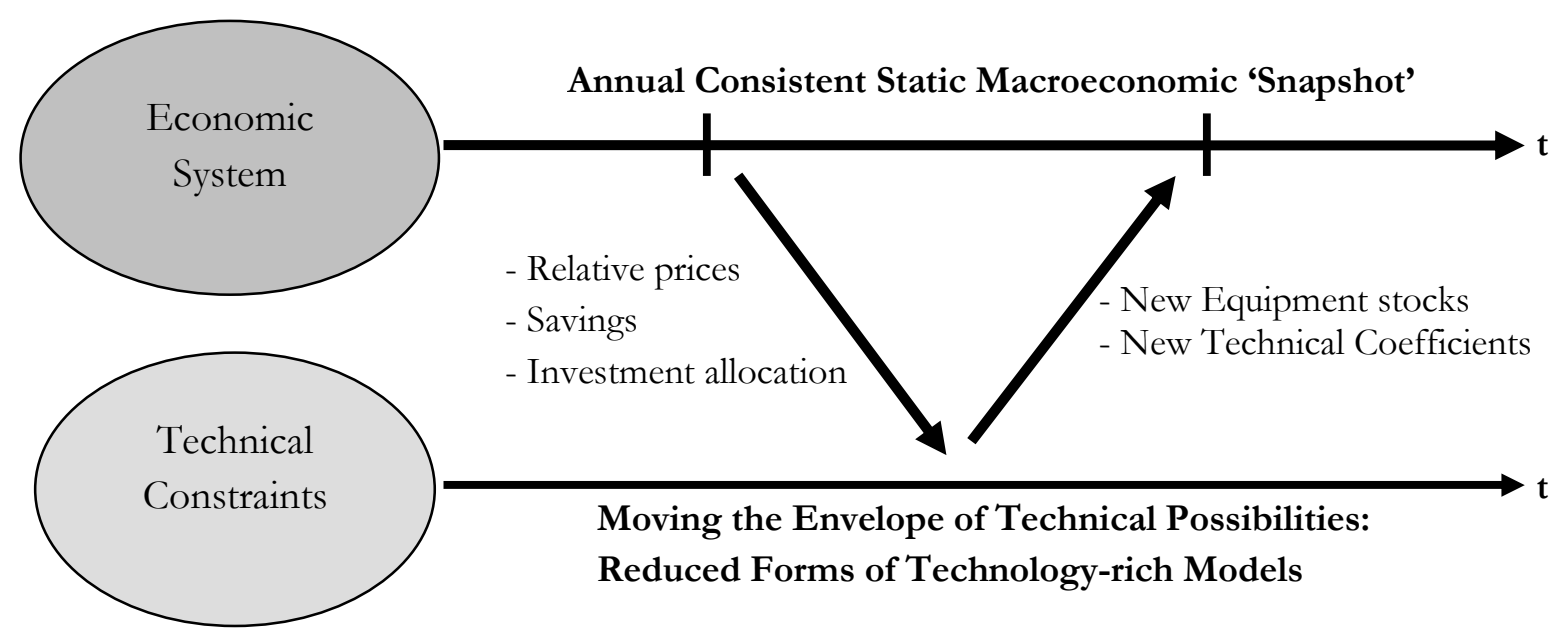

Figure 1: Iterative Top-down / Bottom-Up dialogue in Imaclim-R

This modular structure allows us to avoid the trap of a scale $1 / 1$ map by coupling a rather aggregated static equilibrium with sector-specific bottom-up reaction functions (transportation, energy, land-use) that try and represent explicit and tangible drivers of structural and technical changes. The level of sector aggregation and the sharpness of bottom-up modules can thus be adapted in function of the objective of the modelling exercise. The reduced forms of bottom-up information are designed to reproduce how a given activity responds to economic parameters (price signals, investments). They can be calibrated to approximate the behaviour of detailed bottom-up models. One benefit from the strategy to mimic the response of sector-specific optimizing models is to represent the optimizing behaviour of agents or planners with non perfect foresight, without sticking to an optimal trajectory as a whole.

\footnotetext{
${ }^{4}$ Doing this we neglect the existing possibilities of 'retrofitting' existing capital from one technology to an other one, or from one sector to an other sector. This can be modified easily in the modules describing capital dynamics. In the current version of the model our choice is to represent somehow the upper bound of inertia.
} 


\subsection{A growth engine allowing gaps between potential and real growth}

Conventionally, the growth engine is composed of exogenous demographic trends and labour productivity changes and is fuelled by regional net investment rates and investment allocation among sectors. But, given the intuition that a significant part of total discounted costs after a policy decision or an exogenous shock may be due to transition costs, we seek to capture the latter and we follow Solow's advice (1988) stating that more attention should be devoted to transition pathways, recognizing that economic cycles are not optimal responses to random shocks around an optimal steady state. This calls for a growth engine that permits the existience of endogenous disequilibrium. We thus adopted a "Kaleckian" dynamics in which investment decisions are driven by profit maximisation under imperfect expectations in non fully competitive markets ${ }^{5}$. Disequilibria are endogenously generated by the inertia in adapting to new economic conditions due to non flexible characteristics of equipment vintages available at each period. The inertia inhibits an automatic and costless come-back to a steady state equilibrium. In the short run the main available flexibility lies in the rate of utilization of capacities, which may induce excess or shortage of production factors, unemployment and unequal profitability of capital across sectors. Progress in computational capacity now allows us to run disequilibrium models that do not have the drawback of Harrod-Domar's knife-edged growth to generate structural (and unrealistic) crisis. In IMACLIM-R, we try to overcome this drawback without resorting to the "wrinkle" (Solow, 1988) of the production function which tended to picture frictionless return to the steady state, by construction. Indeed, the growth pathways generated by IMACLIM-R always return to equilibrium in the absence of a new exogenous shock, but after 'some' transition.

\footnotetext{
${ }^{5}$ We are encouraged in this direction by the Stiglitz's remark that some results of neo-classical growth model incorporating costs of adjustment "have some semblance to those of the model that Kaldor $(1957,1961)$ and Kalecki (1939) attempted to construct" which "may be closer to the mark than the allegedly "theoretically correct" neoclassical theory" (Stiglitz 1993, pp 57-58)
} 


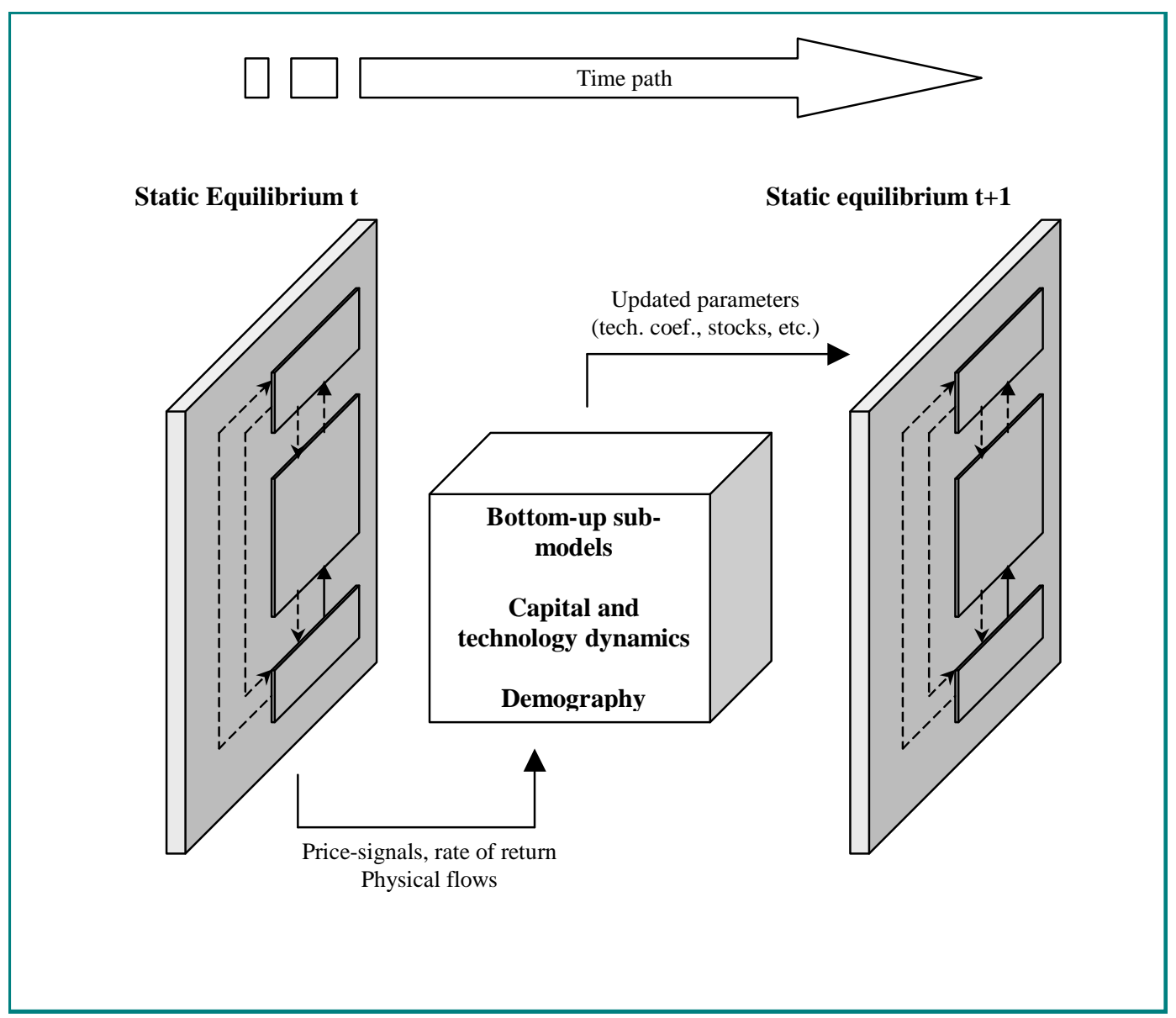

Figure 2 : The recursive dynamic framework of IMACLIM-R

In its current version IMACLIM-R incorporates 12 regions - USA, Canada, Europe, OECD Pacific, Former Soviet Union, China, India, Brazil, Middle East, Africa, Rest of Asia, Rest of Latin America - and 12 productive sectors - Coal, Crude Oil, Natural Gas, Refined products, Electricity, Construction, Agriculture and related industries, Energy-intensive Industries, Air Transport, Sea Transport, Other Transports, Other industries and Services. In addition IMACLIM$\mathrm{R}$ includes transportation with personal vehicles and non-motorized transport. The time-horizon of the model is 2100 .

In the following pages, we describe more precisely the equations of the static equilibrium that determine short-term adjustments and the dynamic modules that condition the motion of growth. Index $k$ refers to regions, indexes $i$ and $j$ refer to goods or sectors, index $t$ refers to the current year and $t_{0}$ to the benchmark year 2001 . 


\section{Main features of the static equilibrium in IMACLIM-R ${ }^{B}$}

The static equilibrium is Walrasian in nature: domestic and international markets for all goods - not including factors such as capital and labour - are cleared by a unique set of relative prices, that depend on the behaviours of representative agents on the demand and supply sides. Those behaviours derive from (i) the maximization of a households' representative utility function under budget constraints, (ii) the choice of the utilization rate of installed production capacities constrained by previous investments and embodied techniques, (iii) the decision routines about government policies, (iv) the commercial and capital flows, (iv) the allocation of investments among domestic sectors. The general structure of this equilibrium is thus a general equilibrium model, in the sense of the original Arrow-Debreu generic framework, which does not necessarily mean full markets equilibrium for all production factors. The calculation of this equilibrium determines the following variables: relative prices, wages, labour, quantities of goods and services, value flows. The following paragraphs detail the specifications of final demand, production, international trade and investment allocation.

\subsection{Households' demand and its partial induction by equipments and infrastructures}

Consumers' final demand results from solving the utility maximization program of a representative consumer. The distinctive features of this program consist in the arguments of the utility function and the existence of two budget constraints. These features are used to capture the induction of final demand by technical change and infrastructures policies, especially in the transportation and energy sectors.

The arguments of the utility function $U$ are the goods $C_{k, i}$ produced by the agriculture, industry and services sectors, with basic needs $b n_{k, i}$ and the services of mobility $S_{k, m o b i l i t y}$ (in passenger-kilometers

\footnotetext{
${ }^{6} \mathrm{~A}$ memo of the equations of the static equilibrium can be found on the website http://www.centre-cired.fr
} 
$p k m)$ and housing $S_{k, \text { bousing }}$ (in square meters). Households thus make a trade-off between the consumption of different goods and services, including the purchase of new end-use equipment stocks.

$$
U=\prod_{\substack{\text { goods } i \\ \text { (ariculture, } \\ \text { industry, } \\ \text { services) }}}\left(C_{i}-b n_{i}\right)^{\xi_{i}} \cdot\left(S_{\text {housing }}-b n_{\text {housing }}\right)^{\xi_{\text {housing }}} \cdot\left(S_{\text {mobility }}-b n_{\text {mobility }}\right)^{\xi_{\text {mobility }}}
$$

Energy commodities are considered as production factors of mobility and housing services: they are not directly included in the utility function, but the associated energy burden weighs on the income constraint. Energy consumption for housing flows from efficiency coefficients characterizing the existing stock of end-use equipments per square meter. The link between mobility services and energy demand is more complex. It encompasses not only the energy efficiency of the vehicles but also the availability and efficiency of four transport modes: terrestrial public transport, air transport, private vehicles and non-motorized. Due to differences in amenities delivered by each mode and to regional particularities, the transport modes are imperfect substitutes. They are therefore nested in a constant elasticity of substitution function.

$$
S_{\text {mobility }}=\operatorname{CES}\left(p k m_{\text {air }}, p k m_{\text {public }}, p k m_{\text {cars }}, p k m_{\text {non motorized }}\right)
$$

This utility function allows an explicit representation of the end-use potential to decouple energy consumption and growth. It is confronted by two budget constraints:

- The income budget (eq. (3)), i.e. the sum of (i) wages received from all sectors $i$ in region $k$ (non mobile labour supply), (ii) dividends (a fixed share of profits within a region) and (iii) lump-sum public transfers must equal all expenditures, including induced energy consumption, plus savings. - A 'travel-time budget' (eq. (4)) justified by empirical findings (Zahavi and Talvitie, 1980) showing the average daily travel time of households in a large panel of cities remains constant over decades. 


$$
\begin{aligned}
\text { Income } & =S+\sum_{\substack{\text { non-energy } \\
\text { non-transport } \\
\text { goods } \mathrm{i}}} \mathrm{p}_{\mathrm{i}} \cdot \mathrm{C}_{\mathrm{i}}+\left(\sum_{\text {energies Ei }} p_{E i} \cdot \alpha_{E i}^{\text {housing }} \cdot \text { stock }^{m^{2}}\right) \\
& +\left(p_{\text {public }} \cdot p k m_{\text {public }}+p_{\text {air }} \cdot p k m_{\text {air }}+\sum_{\text {Fuels Fi }}\left(p k m_{\text {cars }} \cdot \alpha_{F i}^{\text {cars }}\right)\right)
\end{aligned}
$$

where $\mathrm{p}_{\mathrm{i}}$ are prices, stock $\mathrm{m}^{2}$ is the total surface of housing and $\alpha^{\text {bousing }}$ the consumption of each energy product per square meter of housing; $\alpha^{\text {ars }}$ are coefficients describing the mean amount of each energy needed to travel one passenger-kilometer with the current stock of private cars.

$$
\text { Tdisp }=\sum_{\text {Modes Ti }} \int \tau_{j}(u) d u
$$

In IMACLIM-R each transportation mode is characterized by its cost and its travel time efficiency. This parameter is, for each mode, the inverse of the marginal time $\tau_{j}$ used to travel one more kilometre. It depends on both the average speed allowed by the available infrastructures, the speed of vehicles and the gap between modal mobility demand and the capacity of the network. When mobility demand overshoots the normal load condition of the infrastructure, the travel time efficiency of this transportation mode decreases. The investments in transportation can lower the congestion of transportation networks and restore their efficiency. Thanks to this modelling structure, the induction of mobility demand by infrastructure can be captured in longterm scenarios: the deployment of new infrastructures and the availability of more efficient vehicles push households to travel more within their income and time budget. There is thus a positive feedback loop between technical choices in the transportation sector, households' modal choices and overall mobility demand.

\subsection{Static supply curves under fixed productive capacities and technologies}

At each point in time producers are assumed to operate under short-run constraints of (i) a fixed maximal production capacity $C_{a} p_{k, \text { i }}$ defined as the maximum level of physical output 
achievable with the equipments built and accumulated previously, and (ii) fixed input-output coefficients representing that, with the current set of embodied techniques, producing one unit of a good $i$ in region $k$ requires fixed physical amounts $I C_{j, j, k}$ of intermediate goods $j$ and $l_{k, i}$ of labour. In this context, the only margin of freedom of producers is to adjust the utilization rate $Q_{k, i} / C_{a p, i}$ according to the relative market prices of inputs and output. This represents a slightly different paradigm from usual production specifications, since the 'capital' factor is not always fully operated. It seems realistic to assume that short-run adjustments to market conditions consists more in modifications of the level of activity than in changes in the set of techniques used for production within the current year; this seems particularly the case for capital-intensive industries that show a high sensitivity to business cycles.

The partial use of capacities comes from this short-run rigidity of available techniques on the supply side, the utilization rate being determined by the equilibrium between supply and demand. Supply curves are shaped by the existence of static decreasing returns: production costs increase when the capacity utilization rate of equipments approaches one. Following (Corrado and Mattey, 1997), we assume that this is generally caused by higher labour costs due to extra hours with lower productivity, costly night work and more maintenance works. Even though these incremental costs may be also caused by lower mean labour productivity and by higher intermediary consumption, we set a decreasing return parameter $\Omega_{k, i}$ on wages only, at the sector level, for sake of simplicity ${ }^{7}$.

In the current version of the model, all sectors apply a constant mark-up rate $\pi_{k, i}$ to their inputs' costs. In fact such a constant markup corresponds to a static profit-maximization for producers whose decreasing return factor can be approximated by an exponential function of

\footnotetext{
7 The treatment of crude oil production costs is an exception: the increasing factor weighs on the mark-up rate, to convey the fact that oligopolistic producers can take advantage of capacity shortages by increasing their differential rent.
} 
utilization rate ${ }^{8}$. It merely captures the fact that the profitability of a sector increases sharply when the utilization rate of capacities approaches unity. The producer price $p_{k, i}$ is given by the sum of unitary input purchases $p I C_{j, i, k} \cdot I C_{j, i, k}$, unit real labour cost $\Omega_{k, i} w_{k, i} l_{k, i}$ and labour taxes $\operatorname{tax}_{k, i}{ }^{\prime \prime}$, and profit $p_{k, i} \pi_{k, i}$ as shown by the following equation:

$$
\mathrm{p}_{\mathrm{k}, \mathrm{i}}=\sum_{j} \mathrm{pIC}_{\mathrm{j}, \mathrm{i}, \mathrm{k}} \cdot I C_{j, i, k}+\left(\Omega_{\mathrm{k}, \mathrm{i}} \cdot \mathrm{w}_{\mathrm{k}, \mathrm{i}}\right) \cdot l_{k, i} \cdot\left(1+\operatorname{tax}_{k, i}^{w}\right)+\pi_{k, i} \cdot p_{k, i}
$$

This equation represents an inverse supply curve, since it shows how the representative producer decides its level of output $Q_{k, i}$ (which is included in the $\Omega_{k, i}$ factor) in function of all prices and real wages.

\section{2-3 International Markets}

All goods can be exchanged internationally. This means that each component of total demand is composed of both imported and domestic goods. In order to avoid tracking bilateral flows, which is not crucial for the scope of our simulations, all trade flows go through an international market for each good. International trade is then characterized by two parameters: (i) the share of domestic and imported goods in each region and (ii) the share of exports of each region on the international markets.

A well-known modelling issue is how to translate the fact that products are not perfect substitutes. The most usual practice is to adopt an Armington (1969) specification, based on the assumption that the same goods produced in different regions are not perfect substitutes, but can be aggregated in a single quantity index (typically a CES index). It enables the representation of markets in which domestically produced goods keep a share of domestic markets even though

\footnotetext{
${ }^{8}$ Nevertheless, if we rely on this assumption to calibrate the decreasing return factor, its exponent is mathematically dependent on profits' share in total costs in the base year, which is more or less a come back to the unsatisfying 'costs share' rule of calibration of usual production functions.
} 
their price is higher than the world price, and in which different exporters co-exist on the world market even with different prices. We adopt this representation for all non-energy goods.

While ensuring the closure of domestic and international markets in value terms, the Armington specification has the major drawback of not allowing us to sum up international trade flows in physical terms. While this modelling choice can be maintained for generic "composite goods", where quantity units are indexes that are not used directly in the analysis of the economyenergy-environment interfaces, it is not compatible with the need to track energy balances expressed in real physical units. Therefore, for energy goods, we assume a perfect substitutability that makes it relevant to sum all flows. But, to avoid that the cheapest exporter supplies all the market, as the 'utility-based' Armington specification would induce, we rather follow a mere market sharing formula. The international market buys energy exports at different prices and sells at a single mean world price to importers. Shares of exporters on the international market and regional shares of domestic versus imported energy goods depend on relative export prices, export taxes and on market fragmentation parameters calibrated so as to reproduce the existing markets' structure.

For all goods, export prices include the producer prices, export taxes or subsidies, and mean transportation costs. This allows the model to take into account that increasing energy prices would impact on transportation costs and eventually on commercial flows and industrial localization patterns.

\section{2-4 Capital flows and allocation of investment among sectors}

Capital flows, savings and investment depend on various factors such as real interest rates, risk attitudes, anticipations or access to financial markets for individuals, and monetary and fiscal policies, national debt and openness to foreign direct investment at the aggregate level. In spite of this complexity, it is crucial to capture the dynamics of financial flows as they condition the very functioning of the growth engine and the spread of technical change. As previously stressed by 
(McKibbin et al., 1998), the assessment of global energy or climate policies cannot neglect the impact of large shifts in commercial energy flows or of a global tradable permits system on current accounts, on investments and eventually on relative prices. In an attempt to capture these crucial interrelations, we adopted the following default specifications':

(i) Households' savings are assumed to be mostly linked to the dynamics of regional population pyramids. Therefore saving rates are set exogenous, as the demographic trends. Available domestic financial resources for investment are given by the sum of savings and the share of profits that is not redistributed to households.

(ii) Producing sectors formulate anticipations of the investment requirements to expand their production capacity, with imperfect foresight about future prices, profitability rates and demands. In each region we then subtract from available financial resources the sum of all investment needs. Regions showing a surplus of financial resources become net capital exporters and fuel an international capital bundle, which is then allocated to other regions that experience a deficit of financial resources, taking into account durable country-risks that hamper foreign direct investment. This allows us to mimic financial markets where countries (e.g. Brazil) with a lack of savings may raise their interest rates to attract capital inflows and fulfil their financial needs.

(iii) The resulting net available financial resources are allocated among sectors proportionally to their investment needs. Investment is used in each sector to build new production capacities with a new set of technologies, which requires the purchase of different goods most of them from the construction and industry sectors. A crucial parameter is the amount of goods necessary to build a new marginal unit of production in each sector, because it determines both investment needs ex ante and the effective expansion of capacity allowed for a given financial amount expost. In order to be consistent with shifts to more or

\footnotetext{
${ }^{9}$ Contrary to a majority of models, we allow the current account to follow an endogenous behavior, and do not force it to remain constant or to converge to zero. Indeed we observed that some results are very sensitive to the current account's variations, and to the policy routines adopted to control them.
} 
less capital intensive techniques, this parameter is modified according to the new sets of techniques embodied in new capacities, being the precise indicator of the capital deepening associated to technical change.

Eventually, the capital balance is defined by the difference between capital exports and capital imports. By construction, in any general equilibrium, capital balance and commercial balance compensate for each other ${ }^{10}$. This is also the case here, as a result of the conservation of value flows between all agents in each region. Any shift in capital or commercial flows will be counterbalanced by a shift in each region's relative prices, and the subsequent instantaneous modifications of exports and imports.

\section{2-5 Greenhouse gas emissions}

IMACLIM-R computes $\mathrm{CO}_{2}$ emissions from fossil fuel burning, thanks to consistent energy balances and emission coefficients by fuels. The ongoing work on detailed descriptions of industry (see 3.6) and land-use will allow to encompass emissions from industrial processes and land-use management, and for other greenhouse gases. The impact of long-run scenarios on climate is computed by a compact climate model developed at CIRED (Ambrosi et al., 2003).

\section{Dynamics}

The ultimate goal of the model consists in picturing the motion of growth, and both its economic and physical content. This is precisely the role of dynamic modules in the structure shown on Figure 2: while the static equilibrium ensures economic consistency between all flows and relative prices under short-run constraints at each point of time, the dynamic components represent the shift across time of these technology, equipment stock and endowment constraints.

\footnotetext{
10 This accounting rule also holds in the real world but is satisfied also through mechanisms that are not modeled in this version of IMACLIM-R and that would modify the capital account, especially changes in the money stocks of central banks or variations of the external debt.
} 
The interplay of these three elements is ultimately responsible for growth. Below we first explain the representation of the so-called 'drivers of growth', including demography and economic-wide productivity gains, then we detail the modules dedicated to represent sector-specific dynamics.

\subsection{Growth drivers}

In IMACLIM-R economic growth stems from (i) exogenous demographic trends, (ii) labour productivity growth, (iii) capital deepening mechanisms and (iv) hypothesis about the evolution of saving rates.

Exogenous assumptions for demographic trends are derived from UN scenarios corrected with migration flows capable to stabilize populations in low fertility regions, such as Europe. Both active and total populations are concerned: the former drives the available working force in the economy, the latter determines the level of consumption and equipment asymptotes, especially concerning per capita number of cars and square meters, available travel time and food consumption.

Labour productivity growth follows a constant long term rate for the most advanced economy and catching-up assumptions for other regions. More precisely, the baseline trajectory is based on the hypothesis that (i) the United States remain the world productivity leader and their mean labour productivity follows a steady growth of $1.65 \%$ per year, (ii) other countries productivity dynamics are driven by a partial catch-up of productivity gaps, the parameters of which are calibrated on historic trajectories (Maddison, 1995) and 'best guess' of long-term trends (Oliveira-Martins et al., 2005). For policy scenarios, two different specifications were tested in order to focus on endogenous technical change (Crassous et al., 2006): labour productivity was either exogenous or dependent on cumulated regional investment. In the latter case, we tested the crowding-out effect of climate policies on total investment and then productivity growth: we observed it was not dominating in the final bill. 
Besides these long-run drivers, both the availability of investments and their allocation are key elements controlling the effective growth. The amount of investment in each sector drives the pace of productive capacity expansion and the pace of embodied technical change. Productive capacity follows a usual law of capital accumulation with a constant depreciation rate, except Electricity and Industry sectors for which both vintages and equipment lifetimes are fully represented. Sub-sector allocation of investments among technologies is treated in a specific module for each sector, when relevant. The IMACLIM-R architecture currently includes five detailed dynamic modules concerning either supply or final demand for energy: fossil fuel extraction, electricity generation, residential energy uses, transportation and industry. Next development steps are mentioned in the conclusion.

\subsection{Fossil fuels: resources depletion and production costs}

A convincing description of the evolution of coal, oil and gas prices is obviously central for long run energy-economy scenarios. As it was dramatically illustrated by the oil shocks in the 70's, the price of fossil fuels will not only impact on substitution between energies but also on global economic performance, at least as long as fossil fuels keep a central role in the economy (oil fulfils $39 \%$ of total primary energy supply, and $98 \%$ of transportation energy demand). The purpose of this module is thus to capture the main constraints on fossil fuels production and to make explicit the drivers of their prices. In the current version of IMACLIM-R, coal and gas extraction costs are depicted through reduced forms of the energy model POLES (Criqui, 2001), linking extraction costs to cumulated reserves, while crude oil is subject to a detailed treatment which deserves more explanation.

Coming back to equation (5), oil price is the sum of real production costs and the margin applied by producers:

Production costs change with the kind of resource that is exploited. To capture the differentiated characteristics of oil sources (conventional vs. unconventional oil), oil reserves are 
classified in 6 categories according to the cost of putting a barrel at a producer's disposal (including prospecting and extraction). The decision to initiate the production of a given category of resources follows a simple profitability criterion, comparing its total production cost and the current world price of oil.

The profit rate applied by producers depends on the short-run pressure on available production capacities. In other words, the mark-up $\pi$ increases when the ratio of current output to total production capacity approaches unity. A specificity of crude oil is that the availability of production capacity is not only constrained by the amount of previous investments, but also by geological and technical factors that cause intrinsic inertias in the increase of production. Indeed a reserve existing in the subsoil is not entirely and immediately available for extraction. Therefore for a given category of resource in a given region, the available capacity of production is assumed to follow a 'Hubbert' curve. Rehrl and Friedrich (2006) argue that this curve results from the interplay of two contradictory effects: the information effect (finding an oil reserve offers information about the probability of existence of other ones) and the depletion effect (the total quantity of oil in the subsoil is finite). Interestingly this physical interpretation of the 'Hubbert' curve at the 'field' level is not equivalent to empirically assuming the occurrence of a peak of world oil production sometime in the $21^{\text {st }}$ century, which is still controversial.

Moreover, we cannot neglect that the spatial localization of oil production capacities raises sharply the geopolitical stakes. IMACLIM-R is able to capture the impact of various geopolitical scenarios or behaviours: first, the unequal allocation of reserves is captured by an explicit description of available resources in each region; second, endogenous decision routines can mimic the decision to run or not new capacities in OPEC countries - that currently own between $40 \%$ and $50 \%$ of the world total production capacities - and the subsequent market power. 


\subsection{Electricity generation}

Due to its importance in term of energy planning, the power generation sector was historically the focus of important modelling efforts, leading to wide developments of bottom up models of optimal energy planning, up to the large current MARKAL network. Today, this sector is in the centre of debates on climate change policies because of its share in world $\mathrm{CO}_{2}$ emissions (40\% in 2002 (IEA, 2004)). Even from a macro-economic point of view, this sector has a strong influence because of the propagation through the economy of electricity prices variations and its high capital intensity. Indeed, over the next thirty years IEA (2004) forecasts that around 2000 GW of electric generating capacity will have to be built in OCDE countries and $2800 \mathrm{GW}$ in the rest of the world to replace existing capacities or to meet additional demand resulting from economic growth and development. This issue will be all the more critical in a context where strong climate policies could increase the capital costs of new electric generating capacities (shift towards renewable, nuclear or carbon storage technologies).

From a modelling point of view, the electricity sector can not be represented in the same way as other producing sectors. Indeed, as electricity cannot be stored easily, the so-called "load curve" associated with an electrical grid plays a central role in the choice of suitable technologies. The methodological issue is then to model realistically the production of electricity that mobilizes installed producing capacities according to a non-flat load curve.

The electricity supply module in IMACLIM-R tries to tackle this issue of representing the evolution of electric generating capacities over time. When describing annual investment decisions within the electric sector, the model anticipates, ten years forward, the potential future demand for electricity, taking into account past trends of demand. The module then deduces an optimal mix of electricity productive capacities to face the future demand at the lowest cost given anticipated future fuel prices. The optimization process sets not only the total capacity of the 
plants' stock but also its distribution among 26 different power plant technologies (15 conventional including coal-, gas- and oil fired, nuclear and hydro and 11 renewables) whose characteristics are calibrated on the POLES energy sectoral model. The share of each technology in the optimal mix of producing capacities results from a classical competition among available technologies depending on their mean production costs. Moreover, this competition is differentiated whether the capacity is expected to meet peak or base load demand. Technologies with high fixed costs and low variable costs such as nuclear power are more competitive for base load capacities whereas technologies with low fixed costs and high variable costs are likely to be chosen for peak production. This modelling structure also allows the physical constraints to be accounted for - in the absence of a competitive technology for electricity storage - that hamper the extensive deployment of renewable capacities within the electrical grid due to their intermittent production, especially for solar or wind technologies. Once the optimal mix of productive equipment for year $t+10$ has been computed, the new capacity built at year $t$ results from a minimization of the gap between the mix of capacity currently installed and the mix of capacity that is expected to be optimal to face the demand at year $t+10$. This minimization is run under the constraint of the actual amount of capital allocated to the electricity sector. This process of optimal planning with imperfect foresight is repeated at every period and expectations are adapted to changes in prices and demand.

\subsection{Residential energy end-uses}

The residential sector lies at the crossroads of two underlying issues when dealing with projections. On the one hand, it consumes today about $20 \%$ of global primary energy in the world, which suggests it represents an important reduction potential to be considered in the context of climate policies. On the other hand, many development goals are linked to the access to basic end-use energy services, lightning, heating, cooking or refrigeration. This issue is not only an energetic issue as it depends on macroeconomic variables such as per capita income or credit 
availability. Our integrated framework opens the door to a comprehensive assessment of policies in the residential sector, taking into account potential feedbacks between climate protection and development goals.

Total household demand for energy for residential use encompasses various behaviours depending on the end-use considered. Splitting the description by end-use allows the model:

(i) To distinguish basic needs from comfort, characterized by different saturations and income or price elasticities.

(ii) To assess substitution potentials between different energy sources to meet a given energy service. For example, space cooling can be satisfied by no energy but electricity while space heating allows a choice between coal, gas, oil or electricity.

Therefore residential energy demand is disaggregated in six main end-uses whose characteristics are described separately: space heating, cooking, water heating, lighting, space cooling, electrical appliances.

For each of the six end-uses, the final energy service $S E_{i}$ depends on the total number of households $\mathrm{H}$, their equipment rate $\lambda_{i}$ and the level of use of the equipment $e_{i}$ For each energy carrier $j$, the subsequent final energy demand $D E F_{j}$ depends on the shares of the energy mix for each end-use $s h_{i j}$, and on the mean efficiency of equipments $\varrho_{i j}$.

$$
\begin{cases}\text { for each end }- \text { use } & S E_{i}=H \cdot \lambda_{i} \cdot e_{i} \\ \text { for each energy } & D E F_{j}=\sum_{\text {end }-u s e i} s h_{i j} \cdot \frac{S E_{i}}{\rho_{i j}}\end{cases}
$$

For developing countries one major issue is the role and the future of traditional biomass energy. This contribution is often neglected in general equilibrium models as it mainly belongs to the informal sector, yet it remains the most important household energy source for $52 \%$ of the population of non-OECD countries, accounting for $73 \%$ of total residential energy demand for those regions. To include a link between development indexes (among which biomass 
consumption is a good example) and endogenous characteristics of the population (mainly disposable income and inequalities in the distribution of revenues described through a Gini index), we consider that the evolution of the traditional biomass consumption is driven by the share of the population earning less than $2 \$$ a day (IEA, 2002).

\subsection{Transportation}

Long run transportation dynamics raises two critical issues. First, energy supply in the transportation system is likely to remain highly dependent on hydrocarbon fuels due to their high energy density, without any competitive substitute with large scale development prospects. Second, historical $\mathrm{CO}_{2}$ emissions from transportation show vigorous upward trends and final demand patterns reveal low price elasticity even in the long run. Therefore, it is critical to understand mechanisms involved behind the patterns of transportation final demand. They result from the interplay between available vehicle technologies, the pace of penetration of new technologies inside the fleet, the development of infrastructure, land use policies, housing location choices for passenger mobility, and logistics management for freight transportation. Moreover, the high inertia characterizing transportation infrastructure raises risks of 'lock-in' into carbon intensive transportation systems, reporting an increased burden on other sectors for a given $\mathrm{CO}_{2}$ emissions reduction target (Lecocq et al, 1998).

The transportation modelling in IMACLIM- $R$ is an attempt to disentangle specific mechanisms of transportation dynamics. First, the transportation demand described inside the static equilibrium (see 2.1) allows the representation of stylised facts such as the rebound effect or the demand induction by infrastructure that impact both the total mobility and the underlying modal breakdown. Second, the transportation dynamic module alters the constraints applied to transportation demand formation in the static equilibrium: vehicles energy efficiency, households' car equipment, infrastructure policies and evolution of the freight content of economic activity. 
In practical terms, households' time dedicated to mobility evolves correlatively to the total population. The motorization rate is related to the evolution of per capita disposable income with a variable income-elasticity. Indeed, for very poor people, the access to motorized mobility rests on public modes and income-elasticity remains low. Households with a medium per capita income have access to private motorized mobility and the motorization rate becomes very sensitive to variations of income. Finally, for higher per capita income level comparable to OECD's, saturation effects appear and the income elasticity of the motorization rate declines.

Evolution of the energy intensity of the automobile fleet is related to final energy prices through a reaction function calibrated on the energy sectoral model POLES. This function encompasses induced energy efficiency gains for conventional vehicles and the penetration in the fleet of advanced technologies such as electric, hybrid or fuel cells cars. Various policies about investment in transportation's infrastructure can be tested through different routines. In the baseline scenario the building of transportation infrastructure follows the evolution of modal mobility. Air and road infrastructures experience a dramatic increase. The 'other transport' sector gathers road and rail freight transportation, therefore the evolution of its energy input-output coefficients, triggered by final energy prices variations, accounts for both energy efficiency gains and shifts between road and rail modes. This evolution is driven by a reaction function also calibrated on bottom-up information from POLES. Eventually, the evolution of the freight content of the economic growth, which is represented by the transportation input-output coefficients of all the productive sectors in the economy, is an exogenous scenario variable. Indeed it is unclear how to assess how energy prices will affect firms' choices of localisation and production management, but these parameters are likely to play a central role in cost-effective mitigation policies (Crassous et al, 2006). 


\subsection{Agriculture, Industry and Services}

By default, supply-side energy consumption in these three sectors changes according to global energy efficiency improvements and shifts of the energy mix for new vintages of capital. Both are driven by relative prices of energy. On the demand-side, income elasticities of consumption of industrial and agricultural goods are assumed to decline when per capita income increases, in order to represent saturation. It mechanically leads to an endogenous dematerialization.

Nevertheless, the examination of sustainable trajectories representing large departures from baseline trajectories because of dramatic decarbonisation or/and dematerialization trends indicated that the description of industry dynamics should be improved. We indeed need to assess potential reductions of emissions, energy or materials consumption not only in industrial processes themselves, but also those allowed by potential changes in end-use material consumption elsewhere in the economy. As stressed in (Gielen and Kram, 2006), material policies are likely to represent significant low-cost abatement potentials, thanks to dematerialization or trans-materialization. A current research project aiming at exploring the implications of a division by four of GHG emissions in 2050 in Europe for glass, cement, steel, aluminium and refining industries recently led to the development of (i) a bottom-up description of the demand for each of these five products and (ii) reduced forms of detailed model describing technological change in these sectors, that incorporate technical asymptotes, recycling potentials and limitations in energy substitution. Finally, changes on the supply and demand sides for those industrial sectors are re-aggregated to modify the characteristics of the industry sector as a whole in the static equilibrium, in order to ensure full macroeconomic consistency of trajectories. 


\section{Conclusion}

Beside other attempts to bridge the gap between top-down and bottom-up approaches by adapting pre-existing models (Manne et al. 1992, McFarland et al. 2004), the development of the IMACLIM-R framework was conceived in a search for an integrative framework able to simulate long term growth, to represent short-run inertias and to incorporate pieces of expertise about economic behaviour, technical systems or development pathways. As a policy-oriented model, IMACLIM-R aims at facilitating the dialog between economists, engineers and decision makers. As a scientific tool, it tries to reinforce the consistency of long term scenarios, by including the main feedbacks between technology deployment, macroeconomic conditions, and the behaviour of agents with bounded rationality.

In its current state of development, the model now deserves a comparison with other simulation tools to assess how its alternative features modify the evaluation of development, climate and energy policies. It also needs further complementary developments. Some of them are already on track, as a land-use dynamic module - crucial to deliver insights about the competition between food and biofuels for example - and the correction of actual data to take into account the informal economy. Others will be launched in the near future to address current scientific and policy challenges: the adaptation of the Imaclim-R framework to the aggregation level of a country or a big town and, simultaneously, a spatial description of economic activities, especially to deal with the high policy stakes that arise from the intricate dynamics of housing, transportation and material flows. 


\section{References}

Ambrosi P., J.C. Hourcade, S. Hallegatte, F. Lecocq, P. Dumas, M. Ha Duong, (2003), “Optimal control models and elicitation of attitudes towards climate damages", Environmental Modeling and Assessment 8(3): 133-147.

Armington, P. S., (1969). "A Theory of Demand for Products Distinguished by Place of Production." IMF, International Monetary Fund Staff Papers 16: 170-201.

Berndt, E. and Wood, D., (1975). "Technology, Prices and the Derived Demand for Energy", The Review of Economics and Statistics, August, pp 259-268

Crassous, R., Hourcade, J.C., Sassi, O., (2006). "Endogenous Structural Change and Climate Targets. Modeling experiments with IMACLIM-R.” In Edenhofer O., Carraro C., Kohler J. and Grubb M., eds., Endogenous Technological Change and the Economics of Atmospheric Stabilisation. The Energy Journal, Special Issue: 259-276.

Criqui, P., (2001). "POLES: Prospective Outlook on Long-term Energy Systems." Institut d'Économie et de Politique de l'Énergie, Grenoble, France, 9 pp. http://www.upmfgrenoble.fr/iepe/textes/POLES8p_01.pdf (accessed August 2006)

Frondel, M. and Schmidt M. C., (2002). “The Capital-Energy Controversy: An Artifact of Cost Shares?", The Energy Journal Vol.23, Issue 3, 53-79. 
Gielen, D., Kram, T., Ybema, R., (1996), “Integrating Energy and Material Strategies for Greenhouse Gas Reduction: A Promising Challenge”, Change, vol. 30, June.

Hourcade, J.C., (1993). "Modelling long-run scenarios. Methodology lessons from a prospective study on a low CO2 intensive country". Energy Policy 21(3): 309-326.

International Energy Agency (2002), World Energy Outlook, France: Stedi

International Energy Agency (2004), World Energy Outlook, France: Stedi

Jorgenson, D.W. and Fraumeini, B., (1981). "Relative Prices and Technical Change." In E.R. Berndt and B.C. Field (eds.), Modeling and Measuring Natural Resource Substitution. MIT Press, Cambridge MA, United States.

Kaldor, N., (1957), “A Model of Economic Growth”, Economic Journal, 67, in Collected Economic Essays by Nicholas Kaldor, o. c., vol. 2, Essays on Economic Stability and Growth.

Kaldor, N., (1961), "Capital Accumulation and Economic Growth", in F. A. Lutz and D. C. Hague (dir.), The Theory of Capital, New York, St. Martin's Press, 1961, reprinted in Collected Economic Essays by Nicholas Kaldor, o. c., vol. 5, Further Essays on Economic Theory.

Lecocq, F., J.C. Hourcade and M. Ha-Duong, (1998). "Decision making under uncertainty and inertia constraints : sectoral implications of the when flexibility". Energy Economics 20(5/6): 539555. 
Maddison, A., (1995). Monitoring the world economy: 1820 - 1992, OECD Development Center, August 1995, 260 p.

Manne A.S., Wene C.-O., (1992), "MARKAL-MACRO: A Linked Model for Energy-Economy Analysis", Brookbaven National Laboratory, BNL-47161

McFarland J.R., Reilly J.M., Herzog H.J., (2004), "Representing Energy Technologies in Topdown Economic Models Using Bottom-up Information”, Energy Economics 26(4): 685-707.

McKibbin W. J., Shackleton R. ,Wilcoxen P. J., (1998), “The Potential Effects of International Carbon Emissions Permit Trading”, Departmental Working Papers 1998-09, Australian National University, Economics RSPAS.

Oliveira Martins, J., F. Gonand, P. Antolin, C. de la Maisonneuve, and Kwang-Y, (2005). "The impact of ageing on demand, factor markets and growth", OECD Economics Department Working Papers, \#420, OECD Economics Department

Rehrl, T., Friedrich, R., (2006), "Modelling long-term oil price and extraction with a Hubbert approach: The LOPEX model”, Energy Policy, Volume 34, Issue 15, Oct 2006.

Sands, R., D., Miller, S., Kim, .M.-K., (2005). "The second generation model: Comparison of SGM and GTAP approaches to data development", Report for the US Environmental Protection Agency, http://www.epa.gov/oar/sgmdatadevelopment.pdf

Solow, R., (1988), "Growth theory and after", The American Economic Review, 78:3, 307-317. 
Solow, R., (1990). "Reactions to Conference Papers" in Diamond, P. (ed.), Growth, Productivity, Unemployment: Essays to Celebrate Bob Solow's Birthday, The MIT Press.

Weyant et al., (1996). "Integrated Assessment of Climate Change: An Overview and Comparison of Approaches and Results," in Climate Change 1995: Economic and Social Dimensions of Climate Change, J.P. Bruce, H. Lee, E.F. Haites (eds), Cambridge University Press, Cambridge, UK, Chapter 10: Sections 10.1-10.3, pp. 374-380.

Zahavi, Y. and A. Talvitie, (1980). "Regularities in travel time and money expenditures". Transportation Research Record 750, 13土19. 